\title{
The Influence of Silver Nanoparticles Against Toxic Effects of Philodryas olfersii Venom
}

\author{
Jaqueline de Cássia Proença-Assunção' \\ Anna Paula Farias-de-França ${ }^{2}$ \\ Natalia Tribuiani' \\ Jose Carlos Cogo ${ }^{3}$ \\ Rita de Cássia Collaço ${ }^{4}$ \\ Priscila Randazzo-Moura ${ }^{5}$ \\ Sívio Roberto Consonni (iD) ${ }^{6}$ \\ Marco Vinicius Chaud (iD) \\ Carolina Alves dos Santos ${ }^{2}$ \\ Yoko Oshima-Franco (iD) \\ 'Post-Graduate Program in Pharmaceutical \\ Sciences, University of Sorocaba (Uniso), \\ Sorocaba, SP, Brazil; ${ }^{2}$ Pharmacy Graduate \\ Course, University of Sorocaba (Uniso), \\ Sorocaba, SP, Brazil; ${ }^{3}$ Bioengineering and \\ Biomedical Engineering Programs, \\ Technological and Scientific Institute, Brazil \\ University, São Paulo, Brazil; ${ }^{4}$ Department \\ of Pharmacology, Faculty of Medical \\ Sciences, State University of Campinas \\ (Unicamp), Campinas, SP, Brazil; \\ ${ }^{5}$ Department of Surgery, Pontifícia \\ Universidade Católica De São Paulo \\ (PUCSP), Sorocaba, SP, Brazil; ' ${ }^{6}$ epartment \\ of Biochemistry and Tissue Biology, Institute \\ of Biology, State University of Campinas, \\ Campinas, SP, Brazil
}

Correspondence: Yoko Oshima-Franco University of Sorocaba (UNISO), Rodovia Raposo Tavares, Km 92.5, Sorocaba, 18023-000, SP, Brazil

Tel +55 I5 2। I0I-7| 97

Fax $+55 \quad|5-2| 0|-7| 12$

Email yoko.franco@prof.uniso.br
Purpose: A silver nanoparticle obtained by reducing salts with solid dispersion of curcumin $\left(130 \mathrm{~nm}, 0.081 \mathrm{mg} \mathrm{mL}{ }^{-1}\right.$ ) was used to counteract against the toxic - edematogenic, myotoxic, and neurotoxic - effects of Philodryas olfersii venom.

Methods: The edematogenic effect was evaluated by plasma extravasation in rat dorsal skin after injection of $50 \mu \mathrm{g}$ per site of venom alone or preincubated with 1,10 , and $100 \mu \mathrm{L}$ of AgNPs; the myotoxicity was evaluated by measuring the creatine kinase released into the organ-bath before the treatment and at the end of each experiment; and neurotoxicity was evaluated in chick biventer cervicis using the conventional myographic technique, face to the exogenous acetylcholine $(\mathrm{ACh})$ and potassium chloride $(\mathrm{KCl})$ added into the bath before the treatment and after each experiment. Preliminarily, a concentration-response curve of AgNPs was carried out to select the concentration to be used for neutralizing assays, which consists of neutralizing the venom-induced neuromuscular paralysis and edema by preincubating AgNPs with venom for $30 \mathrm{~min}$.

Results: The $P$. olfersii venom-induced edema $(\mathrm{n}=6)$ and a complete neuromuscular blockade $(n=4)$ that includes the total and unrecovered block of $\mathrm{ACh}$ and $\mathrm{KCl}$ contractures. AgNPs produced a concentration-dependent decrease the venom-induced edema $(n=6)$ from $223.3 \%$ to $134.4 \%$ and to $100.5 \%$ after 10 and $100 \mu \mathrm{L}$ AgNPs-preincubation, respectively. The preincubation of venom with AgNPs $(1 \mu \mathrm{L} ; \mathrm{n}=6)$ was able to maintain $46.5 \pm 10.9 \%$ of neuromuscular response under indirect stimuli, $39.2 \pm 9.7 \%$ of extrinsic nicotinic receptors functioning in absence of electrical stimulus and $28.3 \pm 8.1 \%$ of responsiveness to potassium on the sarcolemmal membrane. The $\mathrm{CK}$ release was not affected by any experimental protocol which was like control.

Conclusion: AgNPs interact with constituents of $P$. olfersii venom responsible for the edema-forming activity and neuromuscular blockade, but not on the sarcolemma membraneacting constituents. The protective effect of the studied AgNPs on avian preparation points out to molecular targets as intrinsic and extrinsic nicotinic receptors.

Keywords: chick biventer cervicis, opisthoglyphous snakes, Philodryas olfersii, neuromuscular blockade, silver nanoparticles

\section{Introduction}

Modern technologies such as nanotechnology have been revealed as a potential approach for treating ophidian envenomation - a worldwide and neglected disease whose official treatment is serum therapy ${ }^{1}$ - since these materials have been thought to prevent the spread of venom through the body. ${ }^{2,3}$ This meets with the global strategy of the World Health Organization for the prevention and control of snakebite envenoming. ${ }^{4,5}$

Considering that serum therapy is efficient for systemic but not for local effects and that it must be administered early after envenomation to increase the odds of 
a successful treatment, which is an unfavourable condition to inhabitants of rural areas from many countries, the nanoparticles come as a promising option against snakebites $^{6}$ and have already shown their value with the venoms of Naja nigricollis (Elapidae), ${ }^{2}$ Doboia russellie (Viperidae), ${ }^{7}$ Bothrops jararaca and Bothrops erythromelas (Viperidae), ${ }^{8}$ Bothrops jararacussu (Viperidae), ${ }^{9}$ Daboia russelii (Viperidae) and Naja kaouthia (Elapidae). ${ }^{10,11}$

The reasons for use of the nanoparticles include the venom toxins bridging as the interface for drug delivery and targeted therapy, ${ }^{6}$ as shown with the antigen delivery of encapsulated Naja naja oxiana venom in chitosan nanoparticles targeting tumor cells. ${ }^{12}$ Also, the herbal Vitex negundo gold nanoparticle neutralized the acute toxicity, acute stress, and cytokine response of Naja kaouthia venom, ${ }^{10}$ and the titanium dioxide nanoparticles were used as an antidote against the lethal activity of Daboia russelii and Naja kaouthia venoms. ${ }^{11}$ Likewise, chitosan nanoparticles loaded with $B$. jararaca and B. erythromelas venoms were tested as immunoadjuvants on antivenom production. ${ }^{8}$

Nanoparticles have also been used for more specific objectives. The silver nanoparticles promote protection against the neuromuscular blockade induced by Bothrops jararacussu venom ${ }^{9}$ and the proteolytic effects of Doboia russellie venom, ${ }^{7}$ while abiotic hydrogel nanoparticle mitigates the progression of local tissue damage induced by a diverse array of phospholipases $\mathrm{A}_{2}$ and 3FTX isoforms found in Naja nigricollis venom. ${ }^{2}$

The Colubridae snakes Philodryas olfersii (P. olfersii) and Philodryas patagoniensis (popularly known as green snakes) are opisthoglyphous, considered as not poisonous, ${ }^{13}$ and restricted to South America. Envenomation by these species produces similar effects to those caused by Bothrops sp., which can induce misidentification and consequently the treatment with bothropic antivenom. ${ }^{14-16}$ Although of low occurrence, bites by opisthoglyphous snakes can induce mild to severe symptoms and need to be reconsidered despite their medical importance.

Particularly to P. olfersii, few snakebites were reported in the literature. A retrospective analysis pointed 43 cases treated at Hospital Vital Brazil (Butantan Institute, São Paulo, Brazil) from 1982 to $1990^{17}$ and more cases were reported in the years after. ${ }^{14}$ Besides, death has been reported in Recife (Pernambuco state, Brazil). ${ }^{18}$ The symptomatology following these accidents can include intense local pain, swelling, erythema, and ecchymosis $^{17,19}$ at the site of the bite, but with normal clotting time. ${ }^{19}$ Other studies also reported the venom hemorrhagic, fibrinogenolytic, and edema-forming activities, ${ }^{20}$ besides myotoxicity, ${ }^{21}$ neurotoxicity, ${ }^{22}$ and ability to trigger inflammatory cell infiltration. ${ }^{23}$ Curiously, the venom increases the creatine kinase levels in mice but does not affect isolated mammalian preparation. ${ }^{24}$ Contrarily, it causes head drops and paresis in chick, and an irreversible neuromuscular blockade in avian isolated preparation, ${ }^{24,25}$ perhaps a result of its arboreal ecological niche. ${ }^{26}$

In this context, taking into account the edema-forming activity and the known effects of $P$. olfersii venom on avian preparations, a silver nanoparticle $(130 \mathrm{~nm})$ obtained by reducing salts with solid dispersion of curcumin (Curcuma longa Linn.) and stabilized with Pluronic F68 polymer ${ }^{27}$ was used to counteract the toxic effects (edematogenic, neurotoxic, and myotoxic) of this snake venom since the strategies to minimize the progression caused by snake envenoming, especially regarding local effects, are inexistent and should be of major public health interest.

\section{Materials and Methods}

\section{Silver Nanoparticles}

The comprehensive nanoparticles in this study consist of silver nitrate obtained by reducing salts with solid dispersion of curcumin (Curcuma longa Linn.). All reagents were from Sigma-Aldrich ${ }^{\circledR}$ (Saint Louis, MO, USA), as described by Alves et al. $^{27}$ In this mechanism, it is believed that both the polymeric compound pluronic F68 and curcumin influence the reduction of these salts and subsequent conversion to metallic nanoparticles. ${ }^{28}$ Briefly, using a jacketed glass reactor $(250 \mathrm{~mL})$ coupled to the bath at a temperature of $80-90^{\circ} \mathrm{C}$ under agitation on an orbital shaker were added $45 \mathrm{mg}$ of silver nitrate and $135 \mathrm{mg}$ of solid curcumin dispersion. After $40 \mathrm{~min}$, the solution obtained was removed from the system and left at room temperature to cool. Afterwards, the obtained nanoparticles were characterized by Dynamic Lighting Scattering (DLS, Brookhaven-NanoBrook-90 Plus, New York, USA) showing an average size of $130 \mathrm{~nm}$. The concentration of AgNPs is referred to as being $0.081 \mathrm{mg} \mathrm{mL}^{-1}$ based on elsewhere, ${ }^{29,30}$ but additional experiments are needed to elucidate the real amount. Due to being a complex process where AgNPs, curcumin and pluronic F68 can contribute to results, the nanoparticle AgNPs process obtained was 
not purified, but this does not cancel the importance of the preliminary data described here.

\section{Transmission Electron Microscopy (TEM)}

For this analysis, we used as reference silver nanoparticles obtained by dos Santos et $\mathrm{al}^{29}$ without the presence of curcumin. Thus, a volume of $20 \mathrm{uL}$ of each sample (with or without curcumin) was put on a sheet of Parafilm. Next, a Formvar-carbon coated EM grid (G200H-Cu, Electron Microscopy Sciences $($, Hatfield, USA) was put on top of the drop for $20 \mathrm{~min}$. Then, each grid was carefully let dry for $2 \mathrm{~min}$, followed by 2 washes of milli-Q water. At last, air-dried the grid for $10 \mathrm{~min}$ and stored up to the examination in a LEO 906-Zeiss transmission electron microscope (Carl Zeiss Microscopy GmbH, Germany) at an accelerating voltage of $60 \mathrm{kV}$. TEM was performed at the Electron Microscopy Laboratory of the Institute of Biology from the State University of Campinas.

\section{Philodryas olfersii Venom}

The lyophilized venom of $P$. olfersii results from a pool of adult specimens kept at the serpentarium of the Center for Nature Studies (CEN) kindly donated by Dr José Carlos Cogo, from Universidade Brasil (SP, Brazil). This work is registered at the National System for the Management of Genetic Resources and Associated Traditional Knowledge (SISGEN no. AE18BF2).

\section{Animals}

Chicks HY-line W36 (4-8 days) were supplied by Santa Bárbara Poultry Farming (Sorocaba, SP, Brazil) and housed in metal cages with a sawdust substrate that had free access to food and water ad libitum. The project was approved under protocol 159/2019 by the Ethics Committee on Animal Use - CEUA of the University of Sorocaba - SP.

Male Wistar rats (400-500 g; 3-6 months old) from the animal house of the Faculty of Medical Sciences and Health (Pontificia Universidade Católica de São Paulo, PUC-SP, Sorocaba, Brazil) were treated following the norms of the Research Ethics Commission until the achievement of experiments. The experimental protocols were approved by this institutional Committee for the Care and Use of Experimental Animals under protocol no. 2019/117. The animal experiments were done per the Guide for the Care and Use of Laboratory Animals, ${ }^{31}$ and the Animal Research: Reporting of In Vivo Experiments (ARRIVE) guidelines. ${ }^{32}$

\section{Rat Dorsal Skin Plasma Extravasation}

The rats were anesthetized via inhalation with Isoflurane (BioChimico $^{\circledR}$, Rio de Janeiro, RJ, Brazil) and sodium thiopental (i.p. $50 \mathrm{mg} \mathrm{mL}{ }^{-1}$ ), with maintenance doses if necessary. The dorsal skin was shaved, and the animals received Evan's blue dye $\left(1 \mathrm{~mL} \mathrm{~kg}^{-1}\right)$ by bulbourethral penile vein according to elsewhere. ${ }^{33}$ This was followed by the intradermal injection (fixed volume: $100 \mu \mathrm{L}$ ) of the vehicle (saline control), silver nanoparticles (AgNPs controls) and $P$. olfersii (venom $50 \mu \mathrm{g}$ per site) alone or previous incubated (30 min) with 1,10 , and $100 \mu \mathrm{L}$ of AgNPs, using a random order and balanced site pattern. Thirty minutes later, enough time for the maximal effect of the venom according to Rocha \& Furtado, ${ }^{16}$ the rats were euthanized with an overdose of isoflurane, the dorsal skin was removed, and the diameters of injected sites (Evans' blue halo) were measured using a caliper. Plasma extravasation was expressed as \% of control. Results were compared to saline control. Figure 1 shows an experiment using 8 different experimental protocols $(n=6$, for each group) performed on the dorsum of the rat, namely, in 8 randomized areas of application: 1, saline (control); 2,

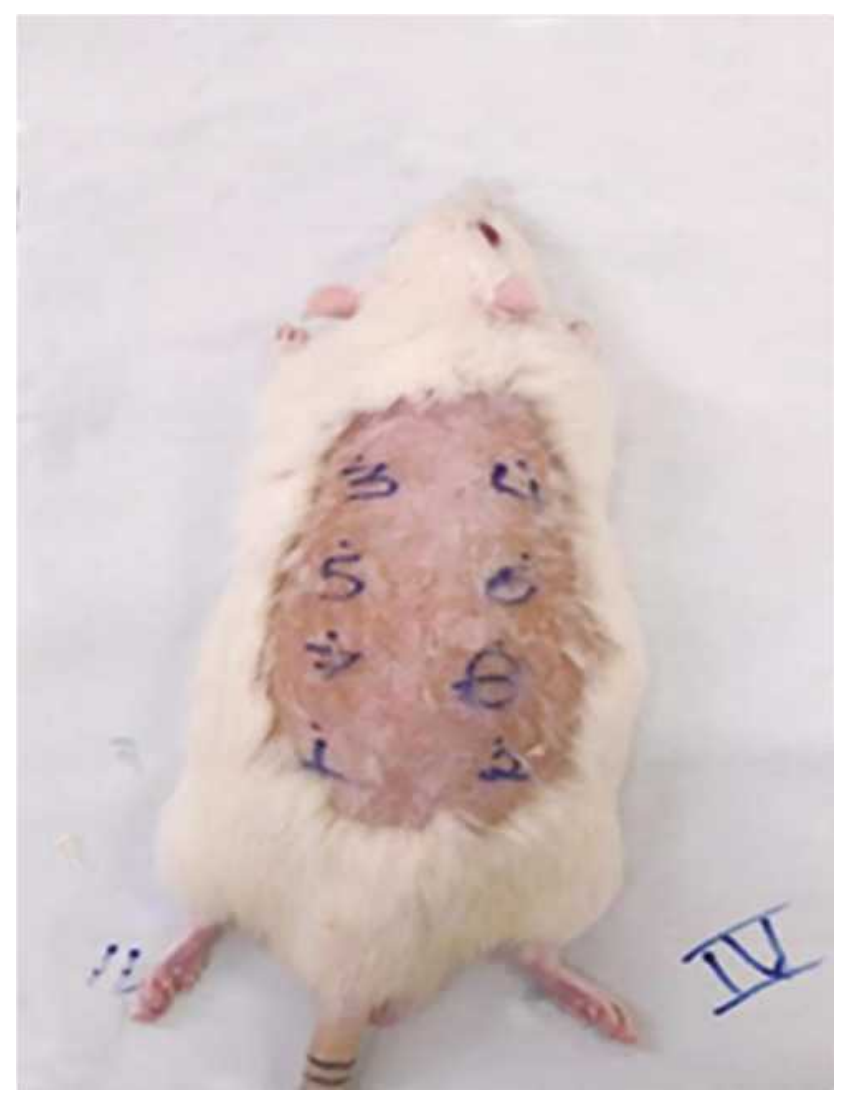

Figure I Epilated area of the rat dorsum for random application of the different protocols ( 1 to 8 ), with $n=6$ for each experimental group. 
Venom alone (50 $\mu$ g per site); 3 , Venom (50 $\mu$ g per site $)+$ AgNPs $(1 \mu \mathrm{L}$ or $81 \mathrm{ng}) ; 4$, Venom $(50 \mu \mathrm{g}$ per site $)+$ AgNPs $(10 \mu \mathrm{L}$ or $810 \mathrm{ng})$; 5 , Venom $(50 \mu \mathrm{g}$ per site $)+$ AgNPs $(100 \mu \mathrm{L}$ or $8100 \mathrm{ng}) ; 6$, AgNPs $(1 \mu \mathrm{L}) ; 7$, AgNPs $(10 \mu \mathrm{L}) ; 8$, AgNPs $(100 \mu \mathrm{L})$.

\section{Chick Biventer Cervicis (BC) Preparation}

Chicks were euthanized via inhalation overdose of isoflurane (BioChimico ${ }^{\circledR}$, Rio de Janeiro, RJ, Brazil) and the biventer cervicis muscles were removed according to Ginsborg \& Warriner ${ }^{34}$ as described elsewhere. ${ }^{35}$ Briefly, the preparation was mounted under a tension of $1 \mathrm{~g}$ per $0.5 \mathrm{~cm}$ in a $5 \mathrm{~mL}$ organ bath (Panlab ${ }^{\circledR}$ Four Chamber Organ Bath) maintained at $37^{\circ} \mathrm{C}$, aerated with carbogen $\left(95 \% \mathrm{O}_{2}\right.$ and $\left.5 \% \mathrm{CO}_{2}\right)$, and kept in a Krebs solution with the following composition (mM, pH 7.5): $\mathrm{NaCl}, 118.1 ; \mathrm{KCl}, 4.8 ; \mathrm{CaCl}_{2}, 2.5 ; \mathrm{MgSO}_{4}$, $1.2 ; \mathrm{NaHCO}_{3}, 25$; and glucose 11.1. A bipolar platinum ring electrode was inserted around the tendon within which the nerve trunk supplying the muscle runs. Field stimulation was done using a Pulse Generator \& Mainframe for up to 4 units (LE12406TC, Panlab $\left.{ }^{\circledR}\right)$ stimulator $(0.1 \mathrm{~Hz}, 0.2 \mathrm{~ms}, 5-12 \mathrm{~V})$. Muscle contractions delivered from "intrinsic" receptors, which respond to the neurotransmitter liberated from the nerve terminal and contractures (depolarizing activity) delivered from "extrinsic" receptors, which respond to acetylcholine added exogenously ${ }^{34,36}$ were recorded isometrically via a force-displacement transducer model MLT0201 (ADInstruments), coupled to a QuadBridge amplifier model FE224 (ADInstruments). The data acquisition was made using a PowerLab 4/35 system model 3504/P connected to a computer unity containing LabChart and LabChart Pro Modules software (ADInstruments). The BC preparations were stabilized for at least $10 \mathrm{~min}$ before the addition of 40 $\mu \mathrm{M}$ acetylcholine (ACh) for 60 seconds (s) or $100 \mathrm{mM}$ potassium chloride $(\mathrm{KCl})$ for the $60 \mathrm{~s}$. Contractures to exogenous $\mathrm{ACh}$ or $\mathrm{KCl}$ were recorded in the absence of field stimulation before the beginning or after the end of each experiment as a test for evaluating pre- or post-synaptic action and, at the same time, the integrity of the sarcolemma. A concentration-response curve was carried out with 1,5 and $25 \mu \mathrm{L}$ of AgNPs, which when added to a bath of $5 \mathrm{~mL}$ capacity, correspond to $0.0162,0.081$, and $0.405 \mathrm{ng} \mathrm{mL}^{-1}$, respectively.

\section{Creatine Kinase (CK) Measurement}

For the quantification of CK activity, samples $(100 \mu \mathrm{L})$ of the $\mathrm{BC}$ bathing solution were withdrawn from the organ bath at 0 (control, after exogenous $\mathrm{KCl}$ and $\mathrm{ACh}$ addition, but before any treatment) and 120 min after each treatment. The withdrawn volume was replaced with an equal volume of Krebs solution. The samples collected were stored for $2 \mathrm{~h}$ at $4^{\circ} \mathrm{C}$ until determining the $\mathrm{CK}$ activity (expressed in $\mathrm{U} \mathrm{L}^{-1}$ ) at $340 \mathrm{~nm}\left(\mathrm{Shimadzu}^{\circledR}\right.$, model multi spec-1501) and at $37^{\circ} \mathrm{C}$, using a commercial kit (CK-NAC REF 11.002.00, BioClin ${ }^{\circledR}$, Belo Horizonte, MG, Brazil).

\section{Data Analysis}

All parameters were expressed as the mean \pm SEM and were compared among groups using Student's $t$-test (contracture responses of $\mathrm{ACh}$ and $\mathrm{KCl}$ in preincubation experiments) or one-way ANOVA followed by the Tukey's test (edema-forming activity, CK release, pharmacological assays and contracture responses of $\mathrm{ACh}$ and $\mathrm{KCl}$ of AgNPs' concentration-response curve) with $\mathrm{p}<0.05$ indicating significance. All data analyses were done using Origin $($ ) v.9.5 (OriginLab Corporation, Northampton, MA, USA).

\section{Results}

An innovative AgNPs obtained with curcumin resulted in an estimated concentration of $0.081 \mathrm{mg} \mathrm{mL}^{-1}$, which corresponds to about $60 \%$ of silver nitrate added in the process, as previously described for other AgNPs obtained in the absence of curcumin. Figure 2 shows a photography's panel obtained through standardized TEM of these nanoparticles to illustrate the success of nanoparticle production, using as reference silver nanoparticles obtained in a similar process, but without curcumin.

As edema is an event that initiates rapidly after a $P$. olfersii snakebite, we hypothesized that the AgNPs could minimize this effect. As such, we evaluated the AgNPs protection resulting from the venom intradermal injection on the vascular permeability in rat skin shown (Figure 3, and Tables S1 and S2). Note that the P. olfersii venom increased plasma leakage to $223.3 \%$ of control and that the inhibition of venom-induced edema by AgNPs was effective with concentrations above $10 \mu \mathrm{L}$ - not statistically significant when compared to saline control.

Ex vivo assays were carried out using the functional chick Biventer cervicis (BC) preparations. Figure 4A shows the concentration-response curve using AgNPs in amounts (in volume) of 1,5 , and $25 \mu \mathrm{L}$ added into the organ-bath $(5 \mathrm{~mL}$ of volume). Note that an amount as small as $1 \mu \mathrm{L}$ of AgNPs (which in $5 \mathrm{~mL}$ contains around $0.0162 \mathrm{ng} \mathrm{mL}^{-1}$ ), selected for further preincubation assays with $P$. olfersii venom, induced a slight but significant 


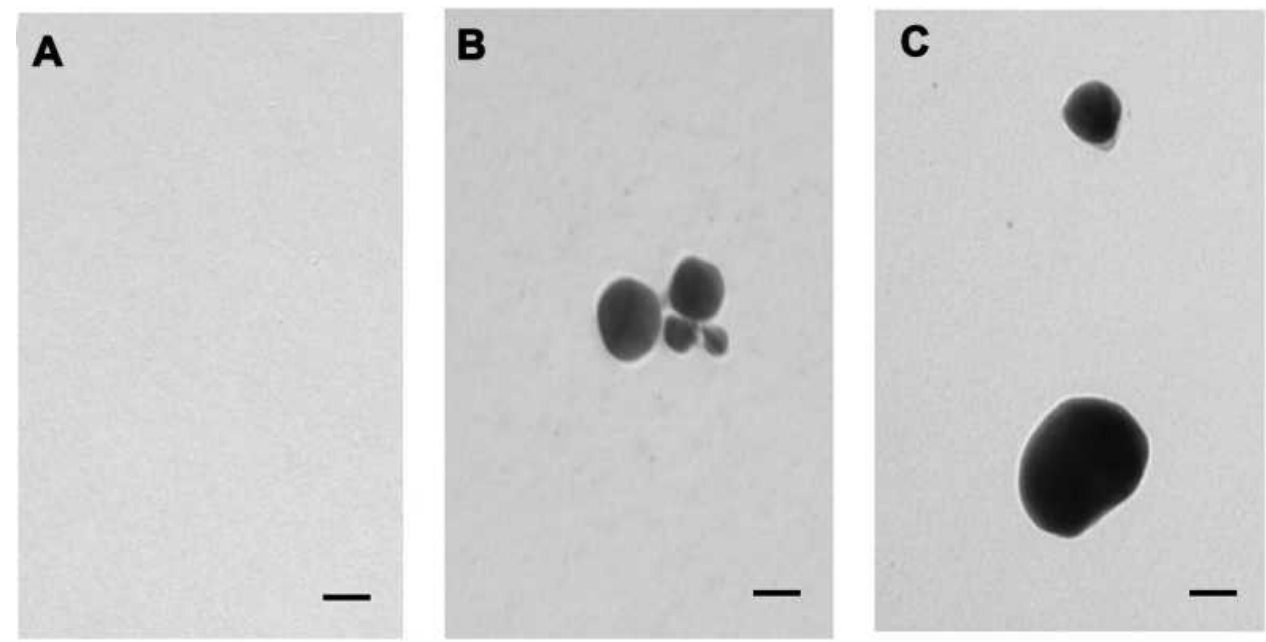

Figure 2 Images obtained from transmission electron microscopy (TEM, $60 \mathrm{kV}$, 100.000X). (A) Milli-Q water. (B) AgNPs $0.08 \mathrm{I} \mathrm{mg} \mathrm{mL}^{-1}$ in absence of curcumin used as a reference. ${ }^{29}$ (C) AgNPs $0.081 \mathrm{mg} \mathrm{mL}{ }^{-1}$ synthetized with curcumin. The latter image denotes the successful production process of curcumin-silver nanoparticles. Bars=200 $\mathrm{nm}$.

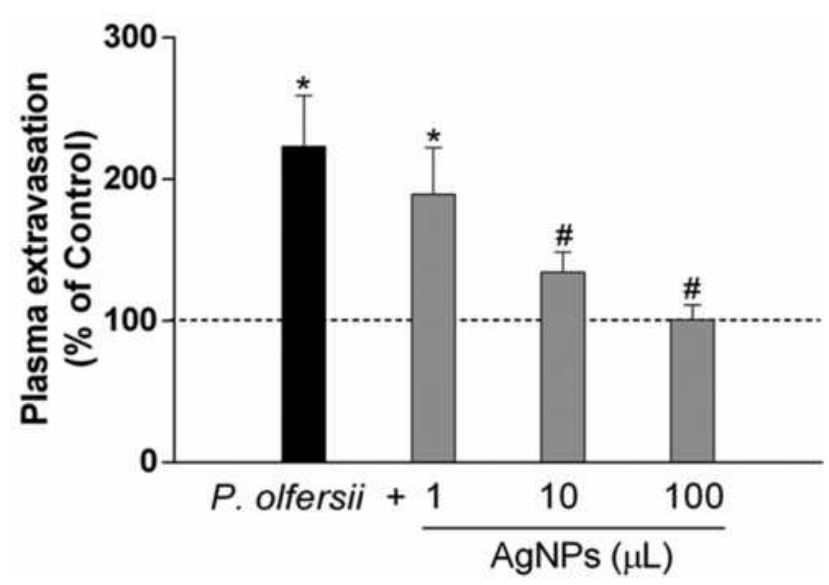

Figure 3 Extravasation of plasma in the dorsal skin of rats. The rats were anesthetized, and the dorsal skin was epilated. The animals received Evan's blue dye $(100 \mu \mathrm{L}$ per $100 \mathrm{~g})$ through the urethral bulb penile vein. Then, they were injected intradermally (fixed volume: $100 \mu \mathrm{L}$ ) of the vehicle (saline control), AgNPs $(\mathrm{I}, 10$, and $100 \mu \mathrm{L})$ and $P$. olfersii venom alone $(50 \mu \mathrm{g}$ per site) or previously incubated $(30 \mathrm{~min})$ with $\mathrm{I}, 10$, and $100 \mu \mathrm{L}$ of $\mathrm{AgNPs}$, using a random order in balanced and standardized sites. Thirty minutes later, the diameter of the injected sites (Evan's blue halo) was measured. Plasma leakage was expressed as a percentage of the control (\% control). The columns represent the mean \pm SEM $(n=6) .{ }^{*} p<0.05$ compared to the control. ${ }^{\#} p<0.05$ compared to the poison.

(compared to Krebs control) neuromuscular blockade of around $24 \pm 12 \%$ at the end of $120 \mathrm{~min}$. The blockade induced by AgNPs was concentration-dependent under indirect stimuli.

The $\mathrm{BC}$ preparations allow interpreting either the indirect evoked stimuli as shown above (Figure 4A), as the contractures induced by exogenous $\mathrm{ACh}$ and $\mathrm{KCl}$ in absence of electrical stimuli (Figure 4B and C, respectively). This is possible since the avian preparation, differently than mammalian tissues, has multiple innervated fibers with a larger number of endplates distributed along its length. In this analysis, otherwise, the silver nanoparticles alone affected only virtually the amplitude of ACh or $\mathrm{KCl}$ contractures since results were not statistically different from Krebs control. The minor concentration of AgNPs was selected for further preincubation assays, by myographical criterium.

In the sequence, we tested the ability of $1 \mu \mathrm{L} \mathrm{AgNPs} \mathrm{to}$ inhibit the neuromuscular activity of $P$. olfersii venom. Figure 5A shows experiments elicited indirectly, resulting in ACh release from terminals in the endplate region. Note the rapid installed neuromuscular paralysis induced by snake venom. The preincubation of AgNPs $1 \mu \mathrm{L}$ with 50 $\mu \mathrm{g} \mathrm{mL}{ }^{-1}$ of venom for $30 \mathrm{~min}$ before the addition into the organ-bath significantly protected the preparation against the neuromuscular blockade induced by the venom alone, maintaining around $46.7 \pm 10.9 \%$ of neuromuscular response at the end of the experiment, under indirect stimulation. Figure 5B shows a characteristic myographical register of $P$. olfersii venom on $\mathrm{BC}$ preparation inducing a rapid increase in the amplitude of twitches followed by a complete and irreversible neuromuscular blockade.

The venom alone abolished completely the contractures in response to both (Figure $5 \mathrm{C}$ and $\mathrm{D}$, respectively). Thus, the preincubation of AgNPs with venom showed the significant protective role of AgNPs, preserving around $39.2 \pm 9.7 \%$ of nicotinic $\mathrm{ACh}$ response, and $28.3 \pm 8.1 \%$ of $\mathrm{KCl}$ sensitivity on the sarcolemma.

Figure 5E shows the obtained results of creatine kinase (CK) activity in aliquots collected from the bath after 

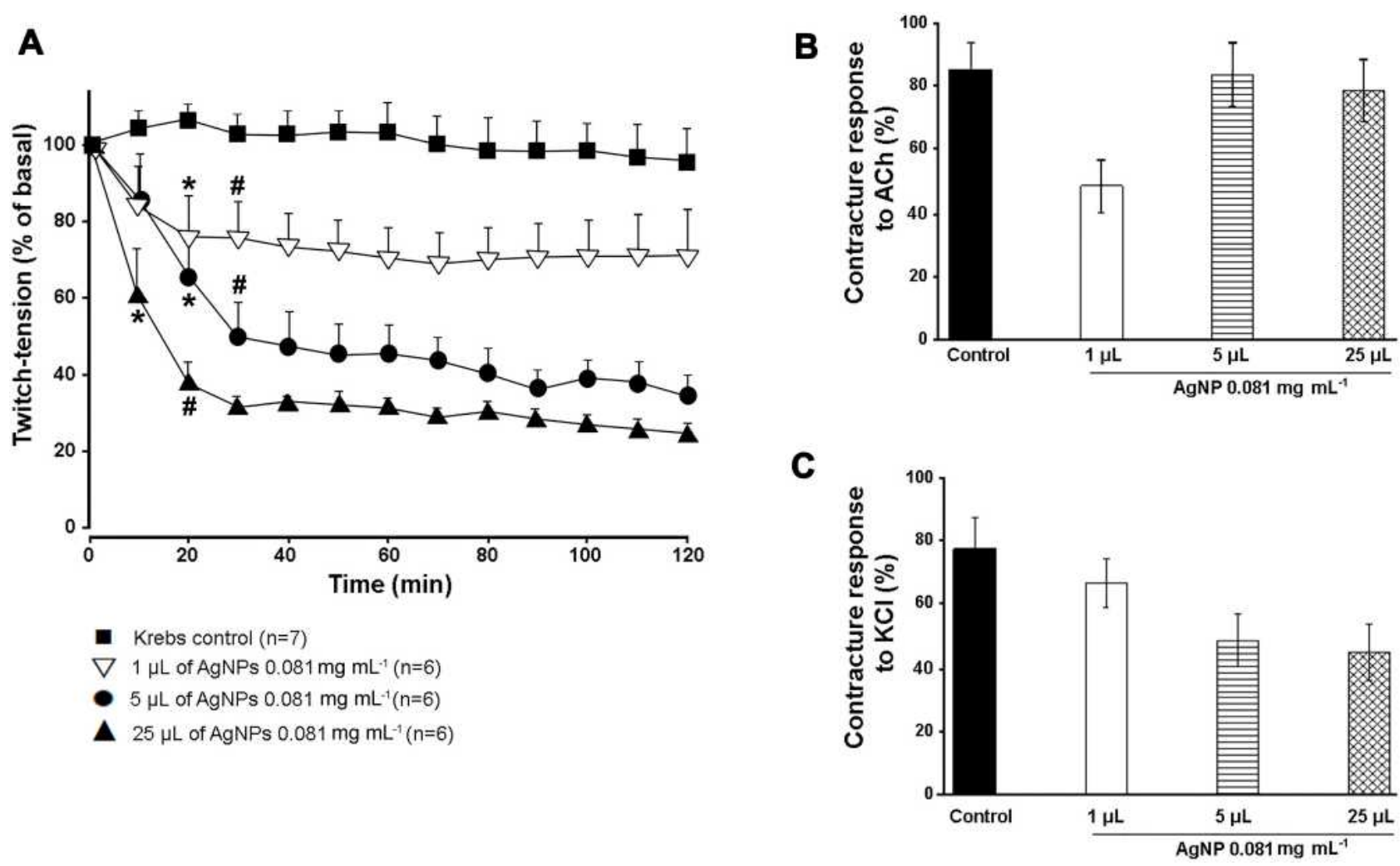

Figure 4 Chick Biventer cervicis preparation. (A) Concentration-response curve of AgNPs under indirect stimuli showing a concentration-dependent effect. (B) and (C) show the contracture response to $\mathrm{ACh}$ and $\mathrm{KCl}$, respectively, being: Krebs control $(n=7) \square$ Venom $(n=4) \square$ AgNPs $0.081 \mathrm{mg} \mathrm{mL} L^{-1}(1 \mu L, n=6)$ 8 Preincubation $(n=6)$. Each point represents the mean \pm SEM. ${ }^{*}<<0.05$ in all subsequent points, and in all concentrations compared to control. ${ }^{\#}<0.05$ compared among AgNPs.

$2 \mathrm{~h}$ of each experimental protocol. Note that no statistical change was observed in treated preparations with AgNPs, venom or preincubated samples (AgNPs + venom) in comparison to the control.

\section{Discussion}

The silver nanoparticles production using a curcumin solid dispersion as a reduction agent is an innovative approach where curcumin substances and pluronic agents can both contribute to AgNPs production, by mechanisms that remain unclear. Here, the protective role of AgNPs was evaluated against the toxic effects of Philodryas olfersii snake venom on mammalian (in vivo) and avian (ex vivo).

Although $P$. olfersii is considered a non-venomous snake, ${ }^{13}$ bites by these opisthoglyphous snakes can lead to misidentification with those caused by the Bothrops genus. ${ }^{14-16}$ Then, to establish differences among them is important to address the appropriate treatment. Differently to Bothrops snakes, $P$. olfersii venom does not cause laboratory abnormalities or coagulation disorders, ${ }^{18}$ but causes other common similar symptoms, such as edema. ${ }^{16,20}$
In this study, the rat dorsal skin model was selected to evaluate the ability of AgNPs in protecting against the venom edema-forming activity, since this is a rapid event experimentally installed after $P$. olfersii injections. Plasma extravasation can have multifactorial causes $^{37}$ as those seen in some snake venoms. ${ }^{38}$ Interactions between platelets and mast cells are among the mechanisms by which snake venoms induce plasma extravasation; this effect, also seems for $P$. olfersii venom, ${ }^{23}$ can lead to hypovolemic shock or hypothermia, along with non-specific tissue injury and inflammation. ${ }^{37,39}$

Considering that nanoparticles have a role in passive (achieved by extravasation through increased permeability of the vasculature) and active (achieved by internalization for expressing their cytotoxic potential) targeting in cancer treatment, ${ }^{40}$ it is attractive to think that silver nanoparticles were able to avoid the edema induced by the $P$. olfersii venom mainly by their passive ability in accessing the venom's compounds and decreasing their toxicities.

Our pharmacological results shown in Figures 4 and 5 were performed in a functional ex vivo chick BC preparation, which allows evaluating the integrity of the 


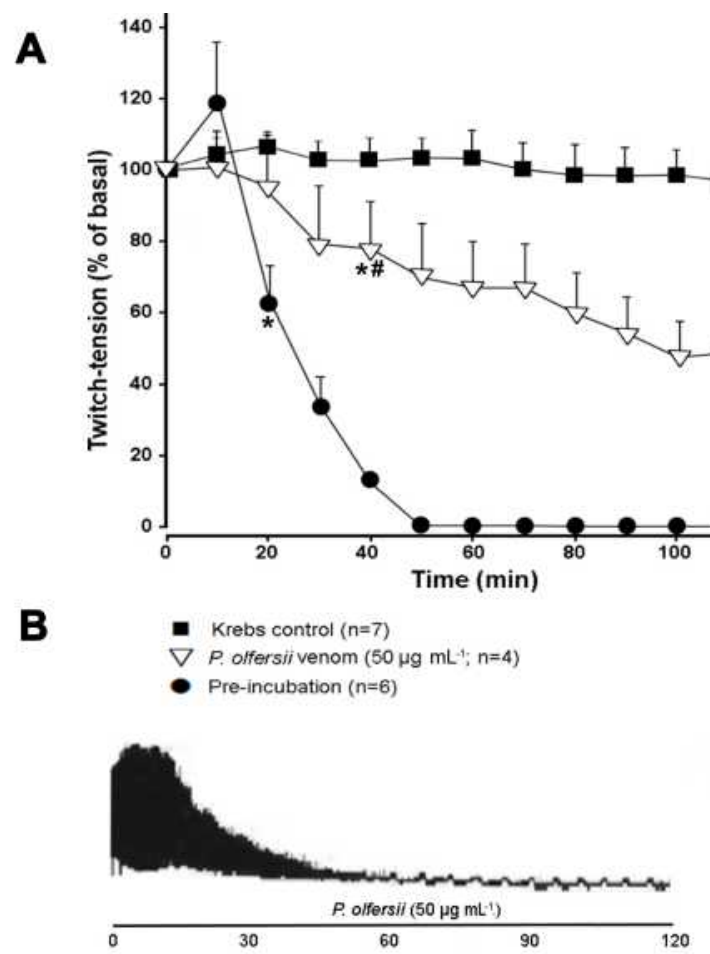

$\mathbf{E}$

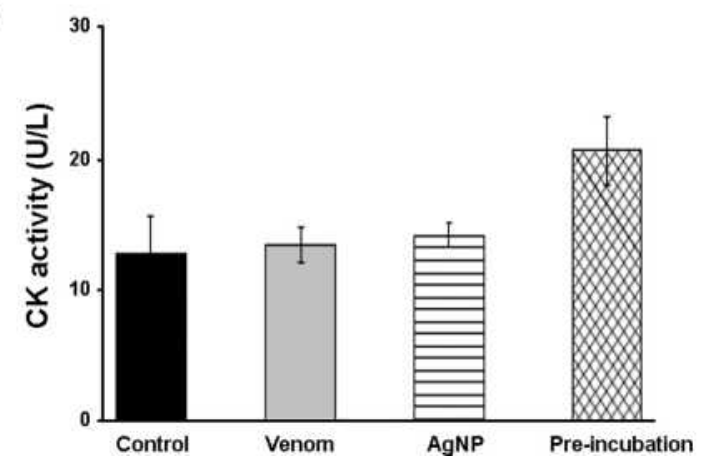

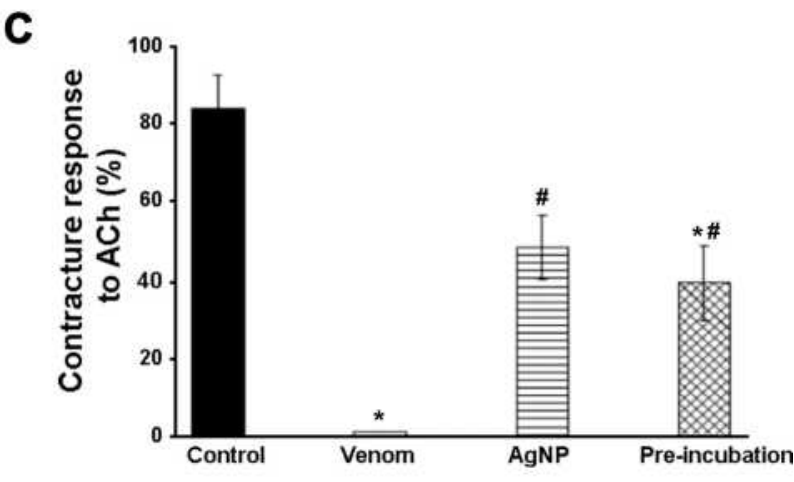

D

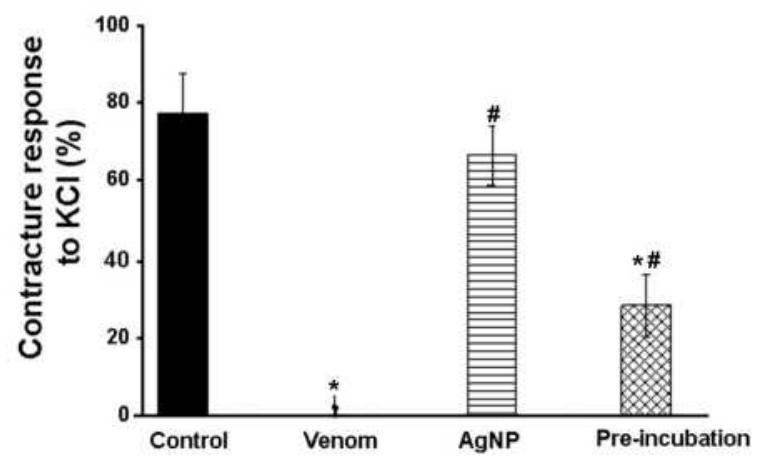

Figure 5 Chick Biventer cervicis preparation. (A) The protection of AgNPs is showed in preincubation experiments. (B) Myographical register showing the irreversible neuromuscular blockade-induced by $50 \mu \mathrm{g} \mathrm{mL} \mathrm{L}^{-1}$ P. olfersii venom. (C) and (D) show the contracture response to $\mathrm{ACh}$ and $\mathrm{KCl}$, respectively, which were blockade by the venom. (E) CK activities of experimental groups. Note that the venom alone did not induce CK release in this experimental model. In preincubation assays the comparison among (A) with (C) and (D) there was a positive correlation between indirect stimulation with exogenous $\mathrm{ACh}$ addition, but not between exogenous $\mathrm{KCl}$ and $\mathrm{CK}$ determination. Each point represents the mean \pm SEM. ${ }^{*} \mathrm{p}<0.05$ in all subsequent points and concentrations compared to control. ${ }^{*} \mathrm{p}<0.05$ compared to the venom. Arrow in $\mathrm{D}$ is indicative of the blockade of the venom.

neuromuscular junction machinery via indirect stimulation and in absent stimulation (face to exogenous addition of $\mathrm{ACh}$ and $\mathrm{KCl}$ ), besides additional ability by direct stimulation by an unknown function independent of the myofiber. $^{41}$

The concentration-response curve of AgNPs showed that 1,5 , and $25 \mu \mathrm{L}$ did not interfere with the contracture response of $\mathrm{ACh}$ nor $\mathrm{KCl}$ (Figure 4B and $\mathrm{C}$ ), comparatively to Krebs control. These results are interesting to evaluate the ability of AgNPs against the total blockade induced by $P$. olfersii venom on the contractile responses (Figure 5A), nicotinic receptors and sarcolemma membrane.

P. olfersii venom is devoid of the enzymatic activities related to phospholipase $\mathrm{A}_{2}$, fibrinogenase, platelet aggregant, nucleotidase, and DNAase. ${ }^{20,42}$ However, the venom expresses serine proteases, metalloproteases, C-type lectins, and high alkaline phosphatase activity. ${ }^{43,44}$ Future studies are needed to correlate which venom component is responsible for the neuromuscular blockade elicited by 
indirect stimuli; still, we observed that the venom fails in inducing such blockade in lower temperatures $<37^{\circ} \mathrm{C}$ (data not shown).

The venom completely blocks the contractures evoked by the addition of exogenous $\mathrm{ACh}$ (Figure $5 \mathrm{C}$ ) and $\mathrm{KCl}$ (Figure 5D) in absence of stimulation. Silver nanoparticles preincubated with venom partially abolished (around 50\%) the blockade indirectly induced by the venom alone (Figure 5B), showing certain efficacy against targets responsible for the paralysis activity. Successful use of polymer nanoparticles to sequester the major protein toxins in elapid snakes was described by O'Brien et $\mathrm{al}^{2}$ but silver nanoparticles certainly display a different interaction with the components of this venom.

In absent stimulation, the AgNPs protection level of ACh-induced contracture $(48.6 \pm 8.4 \%)$ was higher than the $\mathrm{KCl}$ contracture $(28.3 \pm 8.1 \%)$, which shows that the protection was addressed to preserve nicotinic receptors more than the sarcolemma. It also can be interpreted that the venom had minor access to both intrinsic/junctional (elicited by indirect stimulation) and extrinsic/extra junctional (elicited in absence of electrical stimulation face to exogenous ACh addition) postsynaptic nicotine receptors. $^{35,36,45,46}$ The addition of $\mathrm{KCl}$, which directly depolarizes the tissue resulting in muscle contracture, is widely used in Biventer cervicis preparation to evidence the presence of compounds that affects the muscle membrane potential; ${ }^{47}$ a reduction of $\mathrm{KCl}$-induced contracture is indicative of myotoxic damage to tissue. ${ }^{48}$ The results in the present study are consistent with the findings of myotoxins in the Philodryas olfersii Duvernoy's gland secretion, ${ }^{49}$ and myotoxic effects seen in experimental models, ${ }^{21,23,25,50}$ including in human accidents (edema, erythema, ecchymosis, regional lymphadenopathy, neurotoxic and myotoxic effects, but without coagulative disorders). ${ }^{18}$

Yet, these results of exogenous $\mathrm{KCl}$ addition do not correlate with the amount of $\mathrm{CK}$ released into the bath. The reason by which this biomarker was not good to measure the damage caused by this venom may involve a tardive release as shown by Philodryas patagoniensis, ${ }^{51}$ and $P$. olfersii. ${ }^{16}$ In this latter venom, the maximum CK released in blood was obtained after $180 \mathrm{~min}$, whereas our experimental protocols were measured at 2 hours long.

A critical point in this work can be addressed to the presence of curcumin in the colloidal dispersion of AgNPs. Curcumin has been applied to tissue pathologies, ${ }^{52}$ but here there was no protection against the sarcolemma damage induced by venom. On the other hand, it is postulated that curcumin can inhibit phospholipases, metalloproteinases, and protein kinase, ${ }^{53-57}$ which is aligned to this work and could be a positive characteristic of these nanoparticles. Finally, this study also brings to light the use of AgNPs as a co-adjuvant for the treatment of local effects induced by snakebites, which are not effectively neutralized by conventional serum therapy.

\section{Conclusions}

AgNPs interact with constituents of $P$. olfersii venom responsible for edema and neuromuscular blockade, but lesser on the sarcolemma membrane-acting constituents than ACh. The protective effect of the studied AgNPs on avian preparation points out to molecular targets as intrinsic and extrinsic nicotinic receptors.

\section{Acknowledgments}

JCPA was partially supported by Post-Graduation Program in Pharmaceutical Sciences from Uniso (Sorocaba, SP, Brazil); APFF was supported by Fundação de Amparo à Pesquisa do Estado de São Paulo (Fapesp 2019/05891-7); NT was supported by a PhD studentship from Coordination for the Improvement of Higher Education Personnel (CAPES, Brazil). RCC was supported by a Postdoctoral fellowship from the CAPES, Brazil. This work was supported by Fapesp (2012/08271-0). We thank the Electron Microscopy Laboratory at the State University of Campinas (UNICAMP) for access to equipment and technical assistance.

\section{Disclosure}

The authors report no conflicts of interest in this work.

\section{References}

1. World Health Organization. Health topics: snakebite. Available from: https://www.who.int/snakebites/en/. Accessed April 23, 2020..

2. O’Brien J, Lee SH, Gutiérrez JM, Shea KJ. Engineered nanoparticles bind elapid snake venom toxins and inhibit venom-induced dermonecrosis. PLoS Negl Trop Dis. 2018;12(10):e0006736. doi:10.1371/journal.pntd.0006736

3. ScienceDaily. Nanoparticles to treat snakebites. ScienceDaily; 2018 October 4. Available from: www.sciencedaily.com/releases/2018/10/ 181004143920.htm. Accessed April 23, 2020.

4. WHO launches global strategy for prevention and control of snakebite envenoming. WHO Departmental News. 2019 May 23. Available from: https://www.who.int/news-room/detail/23-05-2019-wholaunches-global-strategy-for-prevention-and-control-of-snanebiteenvenoming. Accessed May 23, 2020.

5. Williams DJ, Faiz MA, Abela-Ridder B, et al. Strategy for a globally coordinated response to a priority neglected tropical disease: snakebite envenoming. PLoS Negl Trop Dis. 2019;13(2):e0007059. doi:10.1371/ journal.pntd.0007059 
6. Biswas A, Gomes A, Sengupta J, et al. Nanoparticle-conjugated animal venom-toxins and their possible therapeutic potential. J Venom Res. 2012;3:15-21.

7. Hingane VC, Pangam D, Dongre PM. Inhibition of crude viper venom action by silver nanoparticles: a biophysical and biochemical study. Biophys Physicobiol. 2018;15:204-213. doi:10.2142/ biophysico.15.0_204

8. Soares K, Gláucia-Silva F, Daniele-Silva A, et al. Antivenom production against Bothrops jararaca and Bothrops erythromelas snake venoms using cross-linked chitosan nanoparticles as an immunoadjuvant. Toxins (Basel). 2018;10(4):158. doi:10.3390/ toxins 10040158

9. Oliveira ICF, de Paula MO, Lastra HCB, et al. Activity of silver nanoparticles on prokaryotic cells and Bothrops jararacussu snake venom. Drug Chem Toxicol. 2019;42(1):60-64. doi:10.1080/ 01480545.2018.1478850

10. Saha K, Ghosh S, Ghosh S, Dasgupta SC, Gomes A, Gomes A. Neutralization of Naja kaouthia venom induced toxicity and stress response by Vitex negundo-gold nanoparticle (VN-GNP) in experimental animal model. J Toxins. 2015;2(1):8.

11. Chakrabartty S, Alam MI, Bhagat S, et al. Inhibition of snake venom induced sterile inflammation and $\mathrm{PLA}_{2}$ activity by titanium dioxide nanoparticles in experimental animals. Sci Rep. 2019;9(1):11175. doi:10.1038/s41598-019-47557-y

12. Mohammadpourdounighi N, Behfar A, Ezabadi A, Zolfagharian H, Heydari M. Preparation of chitosan nanoparticles containing Naja naja oxiana snake venom. Nanomedicine. 2010;6(1):137-143. doi:10.1016/j.nano.2009.06.002

13. de Carvalho MA, Nogueira FN. Serpentes da área urbana de Cuiabá, Mato Grosso: aspectos ecológicos e acidentes ofídicos associados [Snakes from the urban area of Cuiabá, Mato Grosso: ecological aspects and associated snakebites]. Cad Saude Publica. 1998;14 (4):753-763.

14. de Araújo ME, Dos Santos AC. Cases of human envenoming caused by Philodryas olfersii and Philodryas patagoniensis (Serpentes: Colubridae). Rev Soc Bras Med Trop. 1997;30(6):517-519. doi:10.1590/S0037-86821997000600013

15. Rocha MM, Paixão-Cavalcante D, Tambourgi DV, Furtado MF. Duvernoy's gland secretion of Philodryas olfersii and Philodryas patagoniensis (Colubridae): neutralization of local and systemic effects by commercial bothropic antivenom (Bothrops genus). Toxicon. 2006;47(1):95-103. doi:10.1016/j.toxicon.2005.10.005

16. Rocha MMT, Furtado MFD. Analysis of biological activities from Philodryas olfersii (Lichtenstein) and P. patagoniensis (Girard) venoms (Serpents, Colubridae). Rev Bras Zool. 2007;24 (2):410-418. doi:10.1590/S0101-81752007000200019

17. Ribeiro LA, Puorto G, Jorge MT. Bites by the colubrid snake Philodryas olfersii: a clinical and epidemiological study of 43 cases. Toxicon. 1999;37 (6):943-948. doi:10.1016/S0041-0101(98)00191-3

18. Correia JM, Santana Neto PL, Pinho MS, Silva JA, Amorim ML, Escobar JA. Poisoning due to Philodryas olfersii (Lichtenstein, 1823) attended at Restauração Hospital in Recife, State of Pernambuco, Brazil: case report. Rev Soc Bras Med Trop. 2010;43(3):336-338. doi:10.1590/S0037-86822010000300025

19. Silveira PV, Nishioka SA. Non-venomous snake bite and snake bite without envenoming in a Brazilian teaching hospital. Analysis of 91 cases. Rev Inst Med Trop Sao Paulo. 1992;34(6):499-503. doi:10.1590/S0036-46651992000600002

20. Assakura MT, Salomão MG, Puorto G, Mandelbaum FR. Hemorrhagic, fibrinogenolytic and edema-forming activities of the venom of the colubrid snake Philodryas olfersii (green snake). Toxicon. 1992;30(4):427-438. doi:10.1016/0041-0101(92)90539-H

21. Acosta de Pérez O, Leiva de Vila L, Peichoto ME, et al. Edematogenic and myotoxic activities of the Duvernoy's gland secretion of Philodryas olfersii from the north-east region of Argentina. Biocell. 2003;27(3):363-370. doi:10.32604/biocell.2003.27.363
22. Rodríguez-Acosta A, Lemoine K, Navarrete L, Girón ME, Aguilar I. Experimental ophitoxemia produced by the opisthoglyphous lora snake (Philodryas olfersii) venom. Rev Soc Bras Med Trop. 2006;39(2):193-197. doi:10.1590/S0037-86822006000200012

23. Oliveira JS, Sant'Anna LB, Oliveira Junior MC, et al. Local and hematological alterations induced by Philodryas olfersii snake venom in mice. Toxicon. 2017;132:9-17. doi:10.1016/j.toxicon.2017.03.013

24. Prado-Franceschi J, Hyslop S, Cogo JC, et al. The effects of Duvernoy's gland secretion from the xenodontine colubrid Philodryas olfersii on striated muscle and the neuromuscular junction: partial characterization of a neuromuscular fraction. Toxicon. 1996;34(4):459-466. doi:10.1016/0041-0101(95)00146-8

25. Collaço RC, Cogo JC, Rodrigues-Simioni L, Rocha T, OshimaFranco Y, Randazzo-Moura P. Protection by Mikania laevigata (guaco) extract against the toxicity of Philodryas olfersii snake venom. Toxicon. 2012;60(4):614-622. doi:10.1016/j. toxicon.2012.05.014

26. Hauzman E, Bonci DM, Grotzner SR, et al. Comparative study of photoreceptor and retinal ganglion cell topography and spatial resolving power in Dipsadidae snakes. Brain Behav Evol. 2014;84 (3):197-213. doi:10.1159/000365275

27. Alves TFR, Das Neves Lopes FCC, Rebelo MA, et al. Crystalline ethylene oxide and propylene oxide triblock copolymer solid dispersion enhance solubility, stability and promoting time-controllable release of curcumin. Recent Pat Drug Deliv Formul. 2018;12 (1):65-74. doi:10.2174/1872211312666180118104920

28. Rachmawati H, Al Shaal L, Müller RH, Keck CM. Development of curcumin nanocrystal: physical aspects. J Pharm Sci. 2013;102 (1):204-214. doi:10.1002/jps.23335

29. Dos Santos CA, Seckler MM, Ingle A, Rai M. Comparative antibacterial activity of silver nanoparticles synthesised by biological and chemical routes with pluronic F68 as a stabilising agent. IET Nanobiotechnol. 2016;10(4):200-205. doi:10.1049/iet-nbt.2015.0 055

30. Alves TF, Chaud MV, Grotto D, et al. Association of silver nanoparticles and curcumin solid dispersion: antimicrobial and antioxidant properties. AAPS PharmSciTech. 2018;19(1):225-231. doi:10.1208/ s12249-017-0832-z

31. National Research Council of the National Academies. Guide for the Care and Use of Laboratory Animals. 8th ed. Washington DC: National Academies Press.; 2011. Available from https:/grants.nih. gov/grants/olaw/Guide-for-the-Care-and-use-of-laboratory-animals. pdf. Accessed September 14, 2019.

32. Kilkenny C, Browne WJ, Cuthill IC, Emerson M, Altman DG. Improving bioscience research reporting: the ARRIVE guidelines for reporting animal research. PLoS Biol. 2010;8(6):e1000412. doi:10.1371/journal.pbio.1000412

33. Brain SD, Williams TJ. Inflammatory oedema induced by synergism between calcitonin gene-related peptide (CGRP) and mediators of increased vascular permeability. $\mathrm{Br} J$ Pharmacol. 1985;86 (4):855-860. doi:10.1111/j.1476-5381.1985.tb11107.x

34. Ginsborg BL, Warriner J. The isolated chick biventer cervicis nerve-muscle preparation. Br J Pharmacol Chemother. 1960;15 (3):410-411. doi:10.1111/j.1476-5381.1960.tb01264.x

35. Tribuiani N, Tavares MO, Santana MN, et al. Neutralising ability of Terminalia fagifolia extract (Combretaceae) against the in vitro neuromuscular effects of Bothrops jararacussu venom. Nat Prod Res. 2017;31(23):2783-2787. doi:10.1080/147864 19.2017.1292506

36. Chang CC, Tang SS. Differentiation between intrinsic and extrinsic acetylcholine receptors of the chick biventer cervicis muscle. Naunyn Schmiedebergs Arch Pharmacol. 1974;282(4):379-388. doi:10.1007/ BF00500986

37. Wick MJ, Harral JW, Loomis ZL, Dempsey EC. An optimized Evans Blue Protocol to assess vascular leak in the mouse. J Vis Exp. 2018;139:57037. doi:10.3791/57037 
38. Nakamura Y, Sasaki T, Mochizuki C, et al. Snake venom rhodocytin induces plasma extravasation via toxin-mediated interactions between platelets and mast cells. Sci Rep. 2019;9(1):15958. doi:10.1038/ s41598-019-52449-2

39. Tsai M, Starkl P, Marichal T, Galli SJ. Testing the 'toxin hypothesis of allergy': mast cells, IgE, and innate and acquired immune responses to venoms. Curr Opin Immunol. 2015;36:80-87. doi:10.1016/j.coi.2015.07.001

40. Cordani M, Somoza Á. Targeting autophagy using metallic nanoparticles: a promising strategy for cancer treatment. Cell Mol Life Sci. 2019;76(7):1215-1242. doi:10.1007/s00018-018-2973-y

41. Cisterna BA, Vargas AA, Puebla C, et al. Active acetylcholine receptors prevent the atrophy of skeletal muscles and favor reinnervation. Nat Commun. 2020;11(1):1073. doi:10.1038/s41467019-14063-8

42. Assakura MT, Reichl AP, Mandelbaum FR. Isolation and characterization of five fibrin(ogen)olytic enzymes from the venom of Philodryas olfersii (green snake). Toxicon. 1994;32(7):819-831. doi:10.1016/0041-0101(94)90007-8

43. Ching AT, Rocha MMT, Paes Leme AF, et al. Some aspects of the venom proteome of the Colubridae snake Philodryas olfersii revealed from a Duvernoy's (venom) gland transcriptome. FEBS Lett. 2006;580(18):4417-4422. doi:10.1016/j.febslet.2006.07.010

44. Sales PB, Santoro ML. Nucleotidase and DNase activities in Brazilian snake venoms. Comp Biochem Physiol C Toxicol Pharmacol. 2008;174(1):85-95. doi:10.1016/j.cbpc.2007.08.003

45. Ginsborg BL. Spontaneous activity in muscle fibres of the chick. JPhysiol. (Lond). 1960;150(3):707-717. doi:10.1113/jphysiol.1960.sp006413

46. Ginsborg BL. Some properties of avian skeletal muscle fibres with multiple neuromuscular junctions. J Physiol. (Lond). 1960;154 (3):581-598. doi:10.1113/jphysiol.1960.sp006597

47. Shieh BH, Pezzementi L, Schmidt J. Extracellular potassium and the regulation of acetylcholine receptor synthesis in embryonic chick muscle cells. Brain Res. 1983;263(2):259-265. doi:10.1016/00068993(83)90318-9

48. Fernandez S, Hodgson W, Chaisakul J, et al. In vitro toxic effects of puff adder (Bitis arietans) venom, and their neutralization by antivenom. Toxins (Basel). 2014;6(5):1586-1597. doi:10.3390/ toxins 6051586
49. Prado-Franceschi J, Hyslop S, Cogo JC, et al. Characterization of a myotoxin from the Duvernoy's gland secretion of the xenodontine colubrid Philodryas olfersii (green snake): effects on striated muscle and the neuromuscular junction. Toxicon. 1998;36(10):1407-1421. doi:10.1016/S0041-0101(98)00075-0

50. Schezaro-Ramos R, Collaço RC, Cogo JC, et al. Cordia salicifolia and Lafoensia pacari plant extracts against the local effects of Bothrops jararacussu and Philodryas olfersii snake venoms. J Venom Res. 2020;10:32-37.

51. Peichoto ME, Leiva LC, Guaimás Moya LE, Rey L, Acosta O. Duvernoy's gland secretion of Philodryas patagoniensis from the northeast of Argentina: its effects on blood coagulation. Toxicon. 2005;45(4):527-534. doi:10.1016/j.toxicon.2004.12.016

52. Dos Santos CA, Rai M, de Oliveira Júnior JM, et al.Curcuminand Related Antioxidants: Applications to Tissue Pathology. Pathology. 1st ed. Elsevier. Vol. 1; 2020:197-204.

53. Yamamoto H, Hanada K, Kawasaki K, Nishijima M. Inhibitory effect on curcumin on mammalian phospholipase D activity. FEBS Lett. 1997;417(2):196-198. doi:10.1016/S0014-5793(97)01280-5

54. Hong J, Bose M, Ju J, et al. Modulation of arachidonic acid metabolism by curcumin and related -diketone derivatives: effects on cytosolic phospholipase A2, cyclooxygenases and 5-lipoxygenase. Carcinogenesis. 2004;25(9):1671-1679. doi:10.1093/carcin/bgh165

55. Lin SS, Lai KC, Hsu SC, et al. Curcumin inhibits the migration and invasion of human A549 lung cancer cells through the inhibition of matrix metalloproteinase-2 and -9 and Vascular Endothelial Growth Factor (VEGF). Cancer Lett. 2009;285(2):127-133. doi:10.1016/j. canlet.2009.04.037

56. Lin JK, Chen YC, Huang YT, Lin-Shiau SY. Suppression of protein kinase $\mathrm{C}$ and nuclear oncogene expression as possible molecular mechanisms of cancer chemoprevention by apigenin and curcumin. J Cell Biochem. 1997; Suppl.28-29:39-48.

57. Ghosh S, Gomes A. Russell's viper (Daboia russelli russelli) venom toxicity neutralizing efficacy of curcumin-gold nanoparticle (C-GNP) in experimental animal model. J Toxins. 2016;3(2):6.
International Journal of Nanomedicine

\section{Publish your work in this journal}

The International Journal of Nanomedicine is an international, peerreviewed journal focusing on the application of nanotechnology in diagnostics, therapeutics, and drug delivery systems throughout the biomedical field. This journal is indexed on PubMed Central, MedLine, CAS, SciSearch ${ }^{\mathbb{}}$, Current Contents ${ }^{\mathbb{R}} /$ Clinical Medicine,
Journal Citation Reports/Science Edition, EMBase, Scopus and the Elsevier Bibliographic databases. The manuscript management system is completely online and includes a very quick and fair peer-review system, which is all easy to use. Visit http://www.dovepress.com/ testimonials.php to read real quotes from published authors. 